\title{
Percepções de professores acerca de um site que discute a pandemia da Covid 19 como questão sociocientífica
}

\section{Teacher perceptions of a site that discusses the Covid 19 pandemic as a socioscientific issue}

${ }^{1}$ Isabel Martins isabelmartins@nutes.ufrj.br

${ }^{1}$ Beatriz Modesto da Silva

${ }^{1}$ Humberto Martins de Souza

${ }^{2}$ Marcelo Borges Rocha

${ }^{1}$ Marcia Regina Garcia

${ }^{1}$ Maria Angélica Mejía-Cáceres

${ }^{3}$ Pedro Miguel Marques da Costa

${ }^{1}$ Rafaela Ferreira dos Santos

${ }^{1}$ Samara Kister

${ }^{1}$ Yasmin Lanatte

\section{RESUMO}

Este trabalho tem objetivo de identificar a percepção dos professores da educação básica sobre o site “Questões Sociocientíficas no Ensino de Ciências” desenvolvido pelo GT Acadêmico do Instituto Nutes de Educação em Ciências e Saúde da UFRJ durante a pandemia da Covid19. No intuito de validar o site, foi aplicado um questionário organizado em quatro blocos:(i) perfil do professor (tempo de magistério, disciplinas que leciona etc.); (ii) estrutura do site; (iii) expectativas, análises dos conteúdos e possibilidades de uso didático do site; (iv) sugestões sobre o site. As análises se organizaram a partir de procedimentos de análise de conteúdo temática de Bardin (2016). Os resultados obtidos indicam que os docentes compreendem o site como fonte de recursos e orientações para práticas pedagógicas, mas também como um espaço que reafirma a autonomia do professor e o caráter autoral da docência. Por fim, observamos que o site foi bem recebido pela maior parte dos docentes, os quais demonstraram perceber a relevância do trabalho curricular com questões sociocientíficas, sobretudo no contexto da pandemia.

Palavras-chave: Questões sociocientífica. Ensino de ciências. Formação docente.

\section{ABSTRACT}

This paper aims to identify the perception of basic education teachers about the "Socioscientific Issues in Science Teaching" website developed during the Covid19 pandemic. To validate the site, a questionnaire organized in four blocks was applied: (i) profile of the teacher (teaching time, subjects he teaches etc.); (ii) questions about the structure of the website; (iii) expectations, content analysis and; (iv) suggestions on the website. The analyzes were organized based on the data corresponding to each session using Bardin's thematic content analysis procedures (2016). The results obtained indicate that teachers can understand the site as a source of resources and guidelines for pedagogical practices, but also as a space that reaffirms the teacher's autonomy and the authorial dimension of teaching. Finally, we observed that the website was well received by most professors, who demonstrated that they perceive how socioscientific issues are relevant, especially in the context of the pandemic.

Keywords: Socioscientific issues. Science teaching. Teacher training.

1 Universidade Federal do Rio de Janeiro

2 Centro Federal de Educação Tecnológica Celso Suckow da Fonseca/Universidade Federal do Rio de Janeiro

3 Centro Federal de Educação Tecnológica Celso Suckow da Fonseca 


\section{CONTEXTO, FUNDAMENTAÇÃO E OBJETIVO DA PESQUISA}

O ano 2020 trouxe consigo a pandemia da Covid-19, que afetou a sociedade em diferentes âmbitos e dimensões sociais. As determinações de distanciamento físico feitas pelas autoridades de saúde impactaram a educação escolar de maneira dramática. Em alguns casos o ensino remoto emergencial foi adotado para dar continuidade ao processo educativo. Se, por um lado, estas ações buscam minimizar perdas decorrentes da interrupção das atividades presenciais, por outro demandam investimentos que permitam o atendimento de grupos sociais economicamente vulneráveis. Em todo caso, constituem-se em um desafio para os professores tanto das escolas como das universidades, que necessitam repensar currículos originalmente elaborados para a modalidade presencial e investir na própria formação para o trabalho pedagógico mediado por diferentes recursos tecnológicos.

Neste texto descrevemos uma experiência de desenvolvimento de um site voltado ao tratamento curricular da pandemia na educação básica elaborado no âmbito do Grupo de Trabalho (GT) Acadêmico do Nutes, um grupo de trabalho instituído pelo Instituto Nutes de Educação em Ciências e Saúde da Universidade Federal do Rio de Janeiro (UFRJ) que envolve pesquisadores e professores, de diferentes áreas de conhecimento, níveis de ensino e experiência profissional. Iniciamos por meio da identificação de desafios que envolvem (i) a formação de professores, (ii) as relações entre pesquisa e ensino e (iii) as potencialidades de tecnologias digitais de informação e comunicação (TDIC) na educação. Em seguida, apresentamos as bases do desenvolvimento do site e sua avaliação por professores de ciências.

\section{1 Desafios da formação de professores}

Segundo Charlot (2006), a educação escolar é um processo de humanização, socialização e inserção na cultura, que ocorre de maneira institucionalizada em nossa sociedade. Políticas educacionais organizam ações voltadas à formação em diferentes níveis e, muitas vezes, propõem articulações entre elas. Um exemplo é a formação de professores da educação básica, que ocorre nas interfaces entre espaços e sujeitos da universidade e da escola de educação básica. Alguns programas de formação, como o Programa Institucional de Bolsas de Iniciação à Docência (PIBID) e a Residência Pedagógica (RP), efetivam uma aproximação entre universidade e escola, espaços que são historicamente marcados por assimetrias e diferentes graus de legitimação social dos saberes neles produzidos (VANDERLINE; VAN BRAAK, 2010).

Nosso ponto de partida, são problematizações e proposições acerca (i) da importância de práticas de colaboração entre universidade - escola na formação inicial e na formação continuada. No âmbito da formação inicial, temos explorado modelos de formação que utilizam a metodologia da codocência (SILVA; SILVA; MARTINS, 2018). Nestas ações, formadores de professores, professores regentes e licenciados se engajam em processos de diálogo e de parceria no planejamento, ensino e avaliação educacional. Nestas interações busca-se estabelecer relações horizontais entre sujeitos, romper com hierarquias e questionar assimetrias de poder. Tais pressupostos também se manifestam nas comunidades de prática, integradas por pesquisadores e professores experientes e em formação -, que desenvolvem atividades de formação colaborativa (LIMA; MARTINS, 2014). Tais aproximações têm sido particularmente importantes pois, não só permitem aos pesquisadores conhecer as demandas e a valorizar saberes escolares, como também promovem o acesso dos professores a pesquisas e inovações educacionais desenvolvidas por especialistas acadêmicos. Constituem-se, assim, em processos nos quais todos os envolvidos aprendem e se formam, valorizando pontos de vista e construindo pontos de consenso.

Apesar de diversos esforços neste sentido, segundo Álvarez e Osoro (2014), existem ainda poucas redes de colaboração entre universidade e escola. Neste sentido, nossas ações buscam promover relações entre estes espaços formativos que permitam estabelecer conexões entre teoria e prática, melhorar a prática docente, repartir a capacidade de decisão, fomentar metodologias horizontais de trabalho e estimular o desenvolvimento profissional docente dos participantes. 


\section{2 Relações entre pesquisa e ensino}

No que diz respeito às contribuições da pesquisa em ensino para o ensino propriamente dito, consideramos que estas envolvem a necessidade de uma recontextualização - ao contrário de uma aplicação - de princípios, práticas e resultados de pesquisa em salas de aula. Os professores podem e devem ser leitores e produtores de pesquisas, avaliando sua pertinência e desdobramentos para o planejamento didático. Pesquisa e docência, se desenvolvidas em ambientes colaborativos, permitem melhor compreensão de aspectos da cultura organizacional da escola e da universidade, bem como das diferenças nos sistemas de avaliação de desempenho profissional de docentes universitários e de docentes da educação básica. Ao (re)significar os sentidos das pesquisas e de seus resultados, os professores podem reforçar seu papel de agentes transformadores de práticas educativas.

\section{3 O trabalho com as TDICs}

No cenário gerado pela pandemia, que implica distanciamento físico, o papel e os usos das tecnologias digitais de informação e comunicação (TDIC) ganharam espaço em discussões educacionais. Se considerarmos a velocidade de propagação das notícias sobre a pandemia, fica evidente o potencial das TDIC no sentido de ampliar o acesso a informações que circulam intensamente na sociedade em diferentes formatos. Além disso, estas tecnologias podem contribuir não só para compartilhar mas também para organizar tais informações, permitindo relações de comparação, contraste, convergência, entre outras.

Estas características motivaram nossa opção pelo desenvolvimento de um site educacional sobre a pandemia da Covid-19, que pudesse ser útil ao professor que necessita realizar buscas, filtrar informações e avaliar sua confiabilidade. Eventualmente, poderia também constituir-se em subsídio para o planejamento de atividades de ensino remoto, que sabemos ser especialmente onerosas em termos de tempo. Por exemplo, a criação de uma videoaula envolve seleção e desenvolvimento de conteúdos, familiarização com ferramentas de captura e edição de som e imagem, preparação de roteiro, pré-produção e edição.

Nossa proposta vai ao encontro do entendimento que são os professores que definem, em diálogo com seus alunos, os sentidos e as possibilidades de recursos digitais. Por esta razão, o papel do professor não se confunde com aquele representado pelos recursos tecnológicos. Ele continua sendo o agente que contribui para a mediação, articulação e integração de experiências escolares com experiências que já fazem parte ou que passam a integrar o mundo da cultura dos alunos (COELHO; CRUZ, 2020).

É claro que a utilização de um site demanda acesso a equipamentos e à internet. Por esta razão, nosso desenho privilegiou um formato simples, que pudesse ser facilmente acessado tanto a partir de celulares como de computadores. Privilegiamos também um formato aberto no qual o professor pudesse encontrar caminhos, problematizadores e propositivos, para o tratamento da pandemia da Covid-19, e não um repositório de recursos instrucionais.

\subsection{O desenho do site}

Em nosso site “Questões Sociocientíficas no Ensino das Ciências” (www.qsc.nutes.ufrj.br) conceituamos a pandemia da Covid-19 como uma questão sociocientífica (QSC). As QSC são um importante programa de pesquisa no campo da Educação em Ciências. Tributário do movimento Ciência Tecnologia e Sociedade (CTS), envolvem questões controversas relacionadas a temas atuais e com importância pública, como o aquecimento global e a poluição. Sua compreensão envolve dimensões científicas, sociais, econômicas, culturais e políticas. Além disso estão presentes nos meios de comunicação e redes sociais. Em outras palavras, envolvem diferentes pontos de vista e têm implicações em uma ou várias áreas do conhecimento. 
Nossa opção por tratar a pandemia da Covid-19 como uma QSC se justifica, pois, ela afeta a saúde de milhões de pessoas e demanda a consideração de questões polêmicas na tomada de decisões por parte de indivíduos e governantes. Por exemplo, as necessárias medidas de isolamento impõem efeitos em diversos setores da economia e, no caso de sociedades marcadas por desigualdades sociais, a pandemia deixa maior quantidade de pessoas na pobreza. Além disso, a busca por tratamentos e vacinas expõe não só características dos processos de produção de conhecimento científico mas também dilemas e valores de ordem ética e moral que se somam à dimensão biológica da pandemia.

No GT, buscamos negociar diferentes perspectivas, estabelecer estratégias para tratar a pandemia na sua integralidade e problematizar relações entre recomendações da pesquisa sobre QSC e as demandas pelo tratamento curricular das mesmas por professores em educação básica. Nesta perspectiva, a proposta e o desenvolvimento do site beneficiaram-se da diversidade de nacionalidades, áreas de formação e atuação profissional e grau de experiência dos integrantes do GT.

O site contempla diferentes insights e recomendações à pesquisa em educação em ciências, como interdisciplinaridade, consideração de aspectos da história e da natureza da ciência, desenvolvimento do pensamento crítico e de habilidades argumentativas, articulando-os em um desenho de inspiração freiriana. Na forma de perguntas que interrogam diferentes aspectos da pandemia, propomos uma leitura de algumas de suas representações e consequências em diferentes âmbitos da sociedade. Por exemplo: problematizamos questões relacionadas à natureza da pesquisa científica frente a indagações acerca do longo tempo envolvido na produção de medicamentos e vacinas que sejam seguros e eficazes; discutimos os argumentos nos quais se baseiam decisões acerca de recomendações por diferentes modelos de isolamento; estabelecemos relações entre esta pandemia e outras que aconteceram na história da humanidade; questionamos as formas de disseminação de notícias - inclusive de notícias falsas -, pelos meios de comunicação e redes sociais.

Trabalhamos com a concepção de um site aberto e de acesso gratuito. Por esta razão, optamos por criar conteúdos e não republicar materiais já disponíveis, apenas indicamos os hiperlinks que permitem seu acesso. Os conteúdos criados na forma de perguntas e respostas enquadram questionamentos e apontam âmbitos relevantes para sua discussão e possível resposta. Esta opção reflete nossa valorização da autonomia dos professores como aqueles que saberão melhor avaliar, junto com seus alunos os âmbitos mais relevantes da pandemia. Também expressa o reconhecimento de que os professores são produtores de saberes que articulam conhecimentos científicos e pedagógicos no contexto da sua docência.

\section{METODOLOGIA: DIALOGANDO COM PROFESSORES SOBRE O SITE}

Para obter informações relevantes para a validação do site como um material educativo elaboramos coletivamente um questionário após consulta a textos da área de metodologia de pesquisa que continham orientações para confecção de questionários. Uma primeira versão piloto do questionário foi distribuída a seis professores participantes de um minicurso oferecido pelo Instituto Nutes sobre QSC no Ensino de Ciências que envolveu a exploração do site, entre outras atividades. A análise das respostas permitiu a reformulação de algumas perguntas, que constaram da versão final do instrumento. Uma adaptação do roteiro proposto por Melo e Bianchi (2015) permitiu relacionar o objetivo do questionário, as hipóteses formuladas pelo grupo, as perguntas de pesquisa, as questões a serem apresentadas aos sujeitos da pesquisa, conforme o Quadro 1. 
Quadro 1: Princípios e procedimentos para elaboração do questionário

\begin{tabular}{|c|c|c|}
\hline Objetivo & Perguntas da pesquisa & Questionário \\
\hline $\begin{array}{l}\text { Avaliar a funcionalidade } \\
\text { prática do site. }\end{array}$ & $\begin{array}{l}\text { O que eu quero saber? } \\
\text { Se o site possui uma estrutura de } \\
\text { fácil navegação. } \\
\text { Pergunta problema: } \\
\text { O que os professores acharam da } \\
\text { navegabilidade do site? } \\
\text { Hipótese: } \\
\text { Os professores tiveram facilidade } \\
\text { para navegar pelo site } \\
\text { (A navegação é intuitiva.) }\end{array}$ & $\begin{array}{l}\text { Perguntas que trarão as respostas } \\
\text { A visualização das páginas é adequada na sua tela? } \\
\text { Sim ou não? Por que? } \\
\text { O layout do site (fonte, cores, menus, figuras etc.) é } \\
\text { adequado? Sim ou Não? Por que? } \\
\text { A navegação entre as páginas do site é fluida (os } \\
\text { caminhos são claros)? Sim ou Não? Por que? } \\
\text { Os hiperlinks são de fácil identificação? Sim ou Não? } \\
\text { Por que? }\end{array}$ \\
\hline
\end{tabular}

Fonte: adaptado de Melo e Bianchi, 2015.

Buscamos perguntas objetivas que não envolveram, mais de uma dimensão de questionamento. O questionário foi organizado em um formulário do Google Forms, dividido em quatro blocos, a saber: (i) perfil do professor (tempo de magistério, disciplinas que leciona etc.); (ii) questões acerca da estrutura do site; (iii) expectativas, análises dos conteúdos e; (iv) sugestões sobre o site.

Na tela de abertura, havia uma saudação aos professores que explicava o objetivo da pesquisa, solicitava autorização para que as respostas fossem incluídas na investigação e oferecia garantia de anonimato aos respondentes. O questionário continha nove perguntas objetivas, do tipo sim/não, com solicitação de justificativa, e quatro abertas. Havia um limite mínimo de 20 caracteres para as justificativas e respostas.

As análises se organizaram a partir dos dados correspondentes a cada bloco do questionário. A partir das tabelas geradas pelo Google Forms, foram calculados os quantitativos das respostas objetivas e analisadas as justificativas e das questões abertas. Para tanto, foram utilizados procedimentos de análise de conteúdo temática (BARDIN, 2016, p.77) que trata-se "da contagem de um ou vários temas ou itens de significação, numa unidade de codificação previamente determinada”. O conjunto dos dados foi analisado pelos autores, que se dividiram em três subgrupos para, de forma independente, para definir unidades de contexto e de registro, e propor categorias empíricas que representassem conjuntos de respostas recorrentes no grupo. Terminada esta etapa os grupos se reuniram e discutiram as categorias propostas. O alto grau de concordância permitiu estabelecer categorias que podem ser consideradas robustas. As perguntas orientadoras da análise foram: (1) Como os professores opinam acerca da legibilidade e da navegabilidade do site? (2) Qual a apreciação dos professores acerca dos conteúdos disponibilizados e do seu potencial para o desenvolvimento de atividades pedagógicas? 


\section{RESULTADOS}

O questionário foi respondido por 19 professores. Um dos professores não autorizou que suas respostas fossem utilizadas na pesquisa e outros dois avaliaram outro site diferente daquele solicitado. Os professores tinham, em média 13,5 anos de experiência no magistério, sendo que o mais experiente tinha 34 e o menos experiente 4 anos. Doze eram professores de Biologia e/ou Ciências e os demais distribuíam-se entre as áreas de pedagogia, direito e artes visuais. Metade dos professores lecionam no ensino fundamental II e os demais se distribuem entre o ensino médio e o ensino fundamental I. Todos os professores lecionam na rede pública, seja no âmbito municipal, estadual ou federal), sendo que sete dos professores também ministram aulas em escolas particulares.

\section{1 Avaliando a estrutura do site}

A maioria dos professores acessou o site pelo celular, apenas um quarto deles o fez pelo computador. Em ambos os casos, todos relataram uma visualização adequada. De forma geral, os professores consideraram o site bem organizado e escrito em linguagem apropriada. Não obstante, encaminharam diversas sugestões sobre possíveis melhorias no layout e navegabilidade. Mostraram-se atentos a aspectos composicionais, como tamanho da fonte, uso de cores e espaçamento, bem como à presença de links em língua estrangeira como fatores a serem revistos de modo a melhorar a legibilidade e não excluir eventuais grupos de leitores:

“Acho que os links poderiam ser mais destacados” (P10)

“A linguagem é adequada, porém alguns links estão em inglês, não sendo acessível a todos” (P11)

A familiarização com aspectos da linguagem multimídia e hipermídia foi lembrada pelos professores como um fator que pode gerar dificuldade a alguns leitores. Por exemplo, a opinião do professor P6 de que "O leitor precisa saber que é um hiperlink, onde ao clicar tem acesso aos conteúdos das perguntas apresentadas”, reforça a percepção de que o uso de TDIC não é ainda plenamente disseminado e demanda um investimento e formação por parte do professor.

Um exemplo de marcador linguístico frequente nas construções dos professores é o uso de conjunções adversativas, como "mas” e "porém”. Em geral, estas são usadas para introduzir uma ressalva após um comentário inicial positivo. Consideramos que tal escolha reflete uma avaliação cuidadosa de possibilidades e limites do site e marca uma possível ambivalência em relação a alguns aspectos que, embora presentes, precisariam ser reformulados.

“No geral, considerei adequado. Mas, atentaria para o espaçamento entre parágrafos em alguns textos (...) e também sugeriria a mudança de layout (quadradinhos coloridos) da página” (P4)

\section{2 Avaliando conteúdo do site}

Percebemos nas falas da maioria dos professores um alto grau de interesse nas QSC de forma geral e em aportes para seu tratamento curricular, como expresso pelo professor P8, ao afirmar que "Seria interessante mais curiosidades, perguntas, sugestões e completar as abas que não estão com conteúdo”. Os professores valorizaram também a possibilidade de “... fazer parcerias com professores de escolas do ensino básico públicas para atuação direta com a formação desses profissionais e pesquisadores da área” (P3) e enfatizaram a necessidade de divulgação do site nas escolas (P13).

No que diz respeito à avaliação que realizaram acerca do potencial e contribuições do site, podemos dizer que as respostas dos professores se organizaram em torno de duas categorias principais, a saber, (i) os conteúdos tratados no site e (ii) as formas de engajamento dos professores com o site. Os conteúdos dizem respeito à natureza, qualidade, pertinência de temas, conceitos, questões pedagógicas, propostas, recursos, entre outros, 
contidos no site. Já as formas de engajamento relacionam-se às percepções dos professores acerca das potenciais contribuições do site para a docência.

Os professores revelaram expectativas em relação aos conteúdos do site por meio de referência a temas e recursos/abordagens pedagógicas, presentes ou ausentes no site. Ao mesmo tempo que destacam a pertinência do tema da pandemia, esperam que o site seja ampliado e sugerem a inclusão de novos temas. A exemplo do professor P5 que destacou “o movimento antivacina; gestão recursos florestais, fake news”, nove professores exemplificaram temas que articulam as áreas de saúde, ambiente, educação midiática. Ao fazê-lo, revelam um entendimento acerca da natureza das QSC que é coerente com as definições das pesquisas da área. Além disso, estabelecem claras relações entre estas questões e outras que atravessam suas realidades educacionais como feito pelo professor P3 ao mencionar “... depressão, doenças neurológicas, bullying, doenças sexualmente transmissíveis, educação sexual...”. Suas sugestões de QSC a serem incluídas no site parecem se relacionar diretamente à desigualdade social e às condições específicas de vulnerabilidade de estudantes de escolas públicas pertencentes a grupos sociais menos favorecidos. A maior frequência de temas mais explicitamente relacionados à saúde e à Biologia pode estar relacionada à maioria dos professores ter formação e/ou atuação profissional nestas áreas.

Observa-se que a expectativa mais frequente entre os professores foi a de encontrar materiais e atividades que pudessem auxiliar na abordagem curricular de QSC, em contextos de ensino presencial e remoto. Em geral, a variedade e a abrangência dos tipos de recursos que integram o site foram objeto de avaliação positiva. Entretanto, sete dos professores, como P3, sentiram a falta de “... mais produtos de pesquisa: jogos, tecnologias no ensino aprendizagem, atividades mais práticas (P3)” e cinco deles, incluindo P4 e P6, sugeriram que o site deveria conter mais imagens e sugestões de atividades práticas e de recursos audiovisuais.

No que diz respeito a abordagens pedagógicas, destacamos as respostas de professores que tiveram atendidas suas expectativas de que o site pudesse ajudá-los a contextualizar o ensino da pandemia no desenvolvimento de suas atividades curriculares. O professor P1 considera que o site promete “... formas de relacionar o cenário atual com o ambiente escolar, o que foi atendido”. Já o professor P10 afirma que a proposta do site ajuda a promover relações entre diferentes áreas de conhecimento por meio do trabalho com “... questões sociocientíficas contextualizadas em atividades práticas de ciências com viés interdisciplinar”.

Apesar da importância e da necessidade de compreendermos aspectos da história e da natureza da ciência e dos processos de produção do conhecimento científico, nenhum professor destacou esta dimensão em suas falas.

\section{3 Avaliando possíveis usos do site}

Todos os professores foram unânimes ao perceber a importância do site como um repositório de informações de caráter conceitual/disciplinar e pedagógico. Nesse sentido, P14 afirmou ter encontrado “... respostas com conteúdo científico para minhas dúvidas”). Já P5 revelou certo grau de desapontamento, visto que imaginava encontrar “... um maior número de questões sociocientíficas disponíveis para consulta.”

Se por um lado, o site foi visto por todos como uma fonte de consulta e informação, por outro, seu uso foi caracterizado de formas distintas. Alguns professores atribuíram um caráter meramente instrumental, por exemplo, na forma de aplicação direta de recursos disponibilizados no site. Outros consideraram-no como um conjunto de orientações, sugestões, parâmetros balizadores, que podem subsidiar a elaboração de novos recursos por parte do professor. Segundo P13, "Podemos fazer adaptações com os textos, elaborar atividades, pesquisas”. A ênfase aqui é na relação entre informações contidas no site e produtos/recursos educativos a serem elaborados pelo professor.

Dois terços dos professores se referiram ao site como um espaço de formação e atualização em sentido amplo. Respostas típicas caracterizavam o site como um local onde seria possível atualizar-se sobre as QSC, ou, nas palavras de P11, "encontrar produção acadêmica, sugestões e materiais didáticos para trabalhar as questões sociocientíficas em sala de aula e/ou remotamente”. Outros, como P10, buscavam encontrar contribuições que 
tornassem “...possível contextualizar as temáticas a temas transversais”) de forma geral, ou inda, como P15, encontrar material adequado às pesquisas do professor. A ênfase aqui é na relação entre as informações contidas no site e seu impacto na formação do professor, mais especificamente na ampliação e no aprofundamento do seu repertório conceitual.

Em síntese, percebemos que a maioria dos professores considera o site como envolvendo dimensões instrumentais e formativas, mas que em ambos os casos não chegam a elaborar exemplos concretos de uso, nomear temáticas específicas ou a explicitar formas de integração da abordagem das QSC no planejamento escolar. São exemplos destas falas de caráter mais geral: "As ideias de como abordar o assunto são fundamentais para uma aula mais dinâmica" (P8) e "Importante ter esses conteúdos organizados, disponibilizados num espaço como este. Os conteúdos são relevantes para construir uma atividade pedagógica comprometida com o ensino e com a formação do estudante.” (P9)

\section{CONSIDERAÇÕES FINAIS}

De forma geral, podemos afirmar que o site foi bem recebido pelos professores e que suas sugestões fornecem elementos concretos que podem subsidiar melhorias. Vimos também que as QSC são vistas como relevantes pelos professores, sobretudo no contexto da pandemia da Covid-19.

Nota-se que os exemplos de QSC mencionados pelos professores são compatíveis com as definições encontradas na literatura na medida que envolvem conceitos científicos, têm importância pública, demandam conhecimentos interdisciplinares e valorizam as realidades locais imediatas bem como questões macrossociais. Percebemos que nas suas avaliações os professores demonstram uma ambivalência em relação ao que esperam das contribuições do site pois, ao mesmo tempo que esperam por orientações e recursos que possam ser aplicados em sala de aula, reafirmam sua autonomia e o caráter autoral da docência. Esta ambivalência não é em si algo negativo, na medida que reflete uma expectativa e valorização de contribuições por parte da universidade e da pesquisa. Destaca-se, ainda, a valorização das experiências colaborativas entre universidade e escola por parte dos professores.

\section{Agradecimentos}

Os autores agradecem à Capes, ao CNPq e à Faperj pelo apoio financeiro. 


\section{REFERÊNCIAS}

ÁLVAREZ, C.; OSORO, J. Colaboración Universidad-Escuela para la innovación escolar. Una investigación acción en proceso. Innovación educativa, n. 24, p 215-227, 2014.

ARAGÃO, J. C. S.; SOARES, G. A. R.; SANTOS, I. X. P.; SOUZA, M. C.; SOUZA, R. S. Produção de vídeos como material didático de apoio para aprendizagem em saúde da mulher: relato de experiência. Revista Práxis, v.11, n. 22, 2019.

BARDIN, L. Análise de conteúdo: edição revista e ampliada. São Paulo: Edições 70, 2016.

CHARLOT, B. A Pesquisa educacional entre conhecimentos, políticas e práticas: especificidades e desafios de uma área de saber. Revista Brasileira de Educação, v.111, n. 31, 2206.

COELHO S.; CRUZ R. Limites e Possibilidades das tecnologias digitais na educação de jovens e adultos. Disponível em: http://www.anped.org.br/sites/default/files/gt18-5049-int.pdf. Acesso em: 28/06/2020.

LIMA, A.; MARTINS, I. O que é uma questão socialmente aguda? Uma análise discursiva a partir de uma comunidade de prática. Revista de Ensino de Biologia da Associação Brasileira de Ensino de Biologia (SBEnBio), v. 7, p. 324-334, 2014.

MARTINS, I.; ROCHA, M.; MEJÍA-CÁCERES, M.; COSTA, P.; MACHADO, S. A pandemia da Covid-19 como questão sociocientífica: aportes do Instituto NUTES para professores e estudantes da Educação Básica. Revista Tecnologia e Sociedade. (no prelo).

MARTINS, I.; LIMA, A. Learning with/from each other: experiences in a collaborative group. In Scantlebury, K. \& Ritchie, S. (eds.) Moving Science Education into the 21st Century: a Festschrift in honor of Kenneth Tobin. Dordrecht: Springer (no prelo).

MELO, W. B.; BIANCHI, C. Discutindo estratégias para a construção de questionários como ferramenta de pesquisa. Revista Brasileira de Ensino de Ciência e Tecnologia. v.8, n.3, p. 43-59, 2015.

SILVA, M. C.; SILVA, G. S. F.; MARTINS, I. Codocência e estágio supervisionado: um processo horizontal de formação de professores. Tecné, Episteme Y Didaxis: Ted (Revista De La Facultad De Ciencia y Tecnología), v. Extra, p. 1-6, 2018.

VANDERLINE, R.; VAN BRAAK, J. The gap between educational research and practice: views of teachers, school leaders, intermediaries and researchers. British Educational Research Journal. v. 36, n.2, p. 299-316. 2010. 